\title{
The Role of Mentoring in a Dual-Mentored Scalable CS Research Program
}

\author{
Christine Alvarado \\ University of California, San Diego \\ cjalvarado@eng.ucsd.edu \\ Diba Mirza \\ University of California, Santa Barbara \\ dimirza@cs.ucsb.edu
}

\author{
Alistair Gray \\ University of California, San Diego \\ ajgray@ucsd.edu \\ Madeline Tjoa \\ University of California, San Diego \\ mjtjoa@ucsd.edu
}

\begin{abstract}
Despite the documented importance of mentoring in undergraduate research, few studies examine how students-especially early undergraduates in computing-perceive their relationships with their mentors. We present a qualitative thematic analysis of the mentoring practices used in an inclusive, structured computer science research program targeting second-year undergraduates across two large public research universities in the United States. Uniquely in this program, students had two mentoring sources: a technical mentor for each research group and a graduate student mentor common to all groups. We analyzed reflections on mentoring from 64 undergraduate researchers at two points in the program. We compared the roles of the two mentors, characterized students' perceptions of both successful and unsuccessful mentors, and examined how mentoring relationships evolved. Generally, students valued mentors who provided project guidance or technical support and who were perceived to be friendly. We found that the roles of the two mentors were complementary in sometimes surprising ways. Overall, our analysis confirms prior work on undergraduate research mentoring, and provides new insights into the unique benefits of a dual-mentoring approach and how to best support early undergraduate computing researchers.
\end{abstract}

\section{CCS CONCEPTS}

-Social and professional topics $\rightarrow$ Computing education programs.

\section{KEYWORDS}

Undergraduate Research; Mentoring; Computing; Diversity; Qualitative Analysis

\section{ACM Reference Format:}

Christine Alvarado, Alistair Gray, Diba Mirza, and Madeline Tjoa. 2021. The Role of Mentoring in a Dual-Mentored Scalable CS Research Program. In Proceedings of the 52nd ACM Technical Symposium on Computer Science Education (SIGCSE '21), March 13-20, 2021, Virtual Event, USA. ACM, New York, NY, USA, 7 pages. https://doi.org/10.1145/3408877.3432364

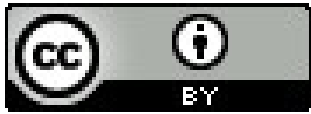

This work is licensed under a Creative Commons Attribution International 4.0 License. SIGCSE '21, March 13-20, 2021, Virtual Event, USA

(C) 2021 Copyright held by the owner/author(s).

ACM ISBN 978-1-4503-8062-1/21/03.

https://doi.org/10.1145/3408877.3432364

\section{INTRODUCTION}

Undergraduate research has many benefits for students in computing, such as increased retention and higher course performance [1, 4], and is particularly beneficial for students from groups underrepresented in STEM and computer science (CS) $[16,17,24]$. Early engagement in CS research specifically may help close sense of belonging gaps for women, Black, Latinx, and Native American students in this field [22].

Strong mentorship is a key part of a successful undergraduate research experience (URE), as high-quality mentoring has been linked to persistence in STEM and other positive outcomes [6, 8, 9, 12]. However, high-quality mentoring, especially of early undergraduates with little disciplinary knowledge, requires significant time and energy. This requirement tends to limit the scalability of many UREs, as few faculty have the time or training to provide sufficient support, and those who do typically mentor only one or two undergraduates at a time. This bottleneck can severely limit computing research opportunities for first and second-year undergraduates, especially those with limited pre-college experience in computing.

To address the mentoring bottleneck, several mentoring structures have been proposed across STEM disciplines (e.g., [3],[7],[20]). Yet there has been relatively little research into the specific impact these structures have on undergraduate researchers in general, and on early undergraduate researchers in computing specifically. In fact, a 2017 National Academies of Sciences, Engineering, and Medicine report on undergraduate research explicitly recommended that "[a]dditional research should examine the specific role(s) of the mentor and the impact of the mentoring relationship on the undergraduate mentee, compared to the immersive [undergraduate research experience] itself" [15].

We examined student perceptions of mentoring relationships in the Early Research Scholars Program (ERSP), a scalable program for early undergraduate research in computing [3]. This program engages approximately $10 \%$ of students in the second year of the computing (Computer Science (CS) and related) major at two US public research-focused universities in a team-based academic-year research apprenticeship. The majority of the participants in ERSP are women and/or Black, Latinx, or Native American. Over its six years, ERSP has shown positive outcomes in terms of student retention, sense of belonging, and performance [1]. We hypothesize that many of these successes are due to the dual-mentoring structure of the program (explained in Section 3), yet to date we did not have a deep understanding of how, or even if, this mentoring structure contributes to the program's success. 
We performed a qualitative thematic analysis of students' openended perceptions of their relationships with their mentors at two points in time: about halfway through, and near the end of the program. As expected, our results support previous findings about mentorship: students value specific direction from their mentors, and appreciate not only technical guidance, but emotional support as well. Our findings also add to our understanding of the relationship between early undergraduate researchers and their mentors. Students found that the two sources of mentoring support were complementary, and we detail the specific value students found from each source of mentoring. Finally, we examine how students' relationships with their mentors developed over time. These results not only support the dual mentoring structure for early undergraduate research, but also provide insight on how mentors can best support early undergraduate researchers.

\section{PREVIOUS WORK}

In this section we examine existing research mentoring structures, and we explore what is known about effective undergraduate research mentoring in computing and STEM more broadly.

\subsection{Mentoring Structures}

Several mentoring structures have been reported in the literature for UREs in STEM. Many of these structures fit into a general model known as Mosaic mentoring, wherein mentoring is carried out through a network of mentors [15]. For example, in an URE in computing based on the Affinity Research Group model [27], students worked in pairs and were mentored by both a faculty member and a graduate student [7]. In another program, Santolucito and Piskac proposed a tiered mentoring structure for high school students and undergraduates involving faculty, graduate students, and peer-mentors [20].

Some structured mentoring programs focus specifically on early undergraduates. Tashakkori et al. advocate for involving undergraduates in early research by describing an academic-year long program for freshman, sophomores, and first year transfer students [25]. Students work in clusters, led by a faculty mentor. ERSP uses a similar split mentoring structure to support early undergraduates in computing [3], and Mirza et al. discuss barriers to early participation in computer architecture research for undergraduates involved in this program [14].

As the above works describe mentoring within the larger context of a URE, the primary focus is on assessing the impact of the URE rather than the mentoring relationships. Most use either reflections on the overall URE experience or survey questions about students' perceptions of the level and quality of mentoring they received, but do not reveal the details of these mentoring relationships.

\subsection{Traits of Effective Mentoring}

More generally, prior work has identified the roles and attributes of effective undergraduate research mentoring from the perspective of students, mentors, or theoretical frameworks. In a qualitative interview-based study of 73 STEM undergraduate researchers, Thiry identified three sets of roles for mentors: professional socialization, intellectual/research support, and personal/emotional support [26]. Pfund et al. expanded these roles to include diversity and sponsorship [18]. Shanahan identified 10 significant evidence-based practices based on a meta-analysis of the literature on undergraduate research mentoring across a broad range of disciplines [21]. In an interview study of 32 exceptional mentors, Walkington identified common best practices-creating challenge, sustaining engagement, and celebrating achievement-and reported that successful mentors create a productive balance between control and freedom [29].

Other works specifically examine aspects of research mentoring in CS. A 4-year study of 117 NSF-funded UREs identified mentoring strategies that promote gender equity in CS: fostering research competence, tracking individual progress, and discussing "safe" topics that relate to both men and women such as work/family balance issues, implicit bias, and stereotype threat [10]. Another large twoyear study of 54 NSF UREs in computing studied the attitudinal shifts that occur for URE participants, and differences in perceptions based on student demographics [19]. Among other results, the authors suggest that a lack of culturally relevant mentoring can lead to a decrease in intent to attend graduate school.

Satisfaction with mentoring relationships has been shown to lead to many positive outcomes for students who participate in STEM UREs, including an increased sense of competency and identity as STEM researchers [28], persistence in STEM [6, 12], and as a predictor in enrolling in doctoral programs [5]. Similar results were reported by Barker in an interview-based study on UREs in CS [2], who found that positive research experiences include mentors providing appropriate scaffolding and career guidance. Negative experiences featured mismatch of expectations between faculty and students, weak mentoring relationships, and students perceiving themselves as being used as "free labor."

\subsection{Relationship to Prior Work}

Prior work generally either studies students' detailed perceptions of a 1-on-1 style mentoring relationship, or evaluates programs involving mentoring structures holistically without studying the studentmentor relationship in detail. We build on prior work by studying the perspectives of early undergraduate researchers in computing on mentoring relationships in a structured, dual-mentored program. Our analysis confirms some of the findings in prior work about the attributes of effective mentors in STEM and CS URE programs [2, 10, 18, 19, 21, 26, 29]. We also present new insights into the roles of mentors, the dynamics that emerge in a dual-mentoring approach, and how mentoring relationships developed over time.

\section{APPROACH}

The context for our study was ERSP, a large-scale academic-year program for primarily second-year undergraduate students in computing and related majors at two large public research universities in the United States [3]. We studied the program in the 2019-2020 academic year, which was the sixth year of the program at one university (UC San Diego) and the second year at the other (UC Santa Barbara).

The program structure was the same at the two universities, and is designed to provide significant structure and support for early career researchers. The program runs for a full academic year, and the key structural components with respect to this study include: 
- Group-based research: Students perform all major research activities in groups of (around) 4, which are stable throughout the program.

- Dual mentorship: Students in the program have two research mentors. Each group has a technical mentor, who is usually a faculty member but sometimes a graduate student or postdoc, leading the research. Groups are also advised by a central mentor, a single graduate student who provides mentoring to all of the groups in the program. Research teams meet with their technical mentor and the central mentor at least weekly for 30-60 minutes throughout the program.

\subsection{Research Questions}

Over the years of running the program, we have observed extremely high retention rates in the program (typically above 95\%), extremely successful research projects, and generally high levels of studentreported satisfaction with the program. We hypothesize that one of the reasons the program is successful for so many students is that the program's mentoring structure gives sufficient support without overwhelming the technical mentors. To investigate how the mentoring structure is working in more detail, we posed the following research questions:

RQ1: What roles do mentors play for the students in this program? RQ2: What is the role of the central mentor vs. the technical mentor and are these roles complementary?

RQ3: How do students' relationships with their mentors change (or stay the same) over the course of the program?

\subsection{Data Collection}

We collected open-ended survey data from students at two points in time: about halfway through the program, when students were in the initial phase of their research (which starts in earnest about 3 months into the 9-month program), and about two months from the end of the program, when they were well into their projects and beginning to end their research activities and write up their work. These points are labeled here as "winter" and "spring". The two surveys were identical, each containing the following questions:

(1) Reflect on your relationship with [your technical mentor] by addressing as many of the following questions/prompts as possible: How well do you think the relationship with your technical mentor(s) is working? Briefly describe your interactions. What type of technical support, if any, does your mentor provide? What type of non-technical support, if any, does your mentor provide? What would you like your mentor to do that they don't currently do?

(2) Now reflect on the advising that [the central mentor] provides by addressing as many of the following questions/prompts as possible. What is working well about the advising the central mentor provides? In what ways does the central mentor's advising complement what your technical mentor provides? What would you change about the support the central mentor provides or what would you like them to do that they are currently not doing?

All responses were individual, but some participants wrote from their personal perspective (e.g. "My relationship with my mentor is...”), while others wrote from their group's perspective (e.g. "Our mentor supports us by...”).

There were in total 65 participants in the programs -49 from UC San Diego and 16 from UC Santa Barbara-all of whom consented to participate in this study. We received complete responses from 64 participants $(98.5 \%)$ in the winter survey and $57(87.7 \%)$ in the spring survey. The percentage of respondents who identify as female was $49 \%$ for the winter and $47 \%$ for the spring. The percentage of respondents who identify as Latinx, Black and/or Native American was $18 \%$ for winter and $19 \%$ for spring.

\subsection{Data Analysis Methods}

We used a deductive thematic analysis approach guided by the research questions above [13], iteratively refining codes and themes through gradual expansion of the data. Initially, all four researchers independently coded $10 \%$ of the winter responses to each question, and then met to discuss the codes and initial themes. They then iteratively refined the codes and themes until a high $(>0.9)$ interrater agreement was reached. Since each response often discussed different aspects of mentoring, we applied multiple codes as needed for each response. Consequently, we used Kraemer's kappa, a refinement of Cohen's kappa appropriate for multi-categorizable coding, to calculate inter-rater agreement [11]. Two of the researchers then repeated this process on $10 \%$ of the data at a time, adding new codes and refining existing codes as needed, until inter-rater reliability on new data consistently surpassed 0.8 , which turned out to be after $40 \%$ of the responses were coded. The remaining responses were then fully coded and differences resolved by consensus.

To specifically examine the quality of students' relationships with their mentors, the two researchers also labeled each response as explicitly positive, neutral, or negative. The neutral categorization was used for purely descriptive responses, while we required explicit affect to label responses as positive or negative. For example, a response beginning "He is doing everything right. [Central mentor] is awesome, please give him a raise." was labelled positive, while one stating "The relationship works." was labelled neutral. We supplemented this analysis with demographic data and information on which students shared research groups.

\section{RESULTS}

\subsection{RQ1: Mentors' Roles}

Our thematic analysis revealed 31 codes, which fell into into five higher-level themes. These are summarized in Table 1, along with the count of code occurrences for the 29 codes used more than once.

We found that the vast majority of mentoring relationships were functional. Of the 241 responses collected, 114 were explicitly positive, 118 were neutral, and only 9 expressed negative perceptions of mentors. In addition, Table 1 shows that the negative codes (e.g. "Unhelpful meetings", which sometimes appeared in an overall neutral relationship) were relatively infrequent.

The most prominent mentoring themes-Project Guidance and Technical-related to direct support with research planning and execution, where the mentors seem to be playing the role of "teacher." By far the most frequently-cited kind of guidance provided by mentors was guidance on what to do next, usually in the short term. 
Table 1: Mentoring themes and associated codes

\begin{tabular}{|c|c|c|c|}
\hline Theme/Code & Winter & Spring & Total \\
\hline Project Guidance & 158 & 130 & 288 \\
\hline Guidance on next steps & 59 & 59 & 118 \\
\hline Constructive feedback & 22 & 19 & 41 \\
\hline Big-picture context & 20 & 16 & 36 \\
\hline Points to other resources & 17 & 11 & 28 \\
\hline Asks questions & 16 & 9 & 25 \\
\hline Not enough guidance & 20 & 3 & 23 \\
\hline Poster/paper help & 0 & 11 & 11 \\
\hline Mentor expectations too high & 4 & 2 & 6 \\
\hline Technical & 126 & 95 & 221 \\
\hline Provides technical support & 49 & 42 & 91 \\
\hline Answers questions & 26 & 21 & 47 \\
\hline Teaches content & 28 & 19 & 47 \\
\hline Not enough technical support & 12 & 2 & 14 \\
\hline Background in other fields & 6 & 7 & 13 \\
\hline No technical support needed & 5 & 4 & 9 \\
\hline Interpersonal & 75 & 70 & 145 \\
\hline Friendliness/emotional support & 32 & 30 & 62 \\
\hline Good communication & 12 & 14 & 26 \\
\hline Liaison between advisors & 10 & 10 & 20 \\
\hline No non-technical support & 8 & 5 & 13 \\
\hline Advisors aren't on same page & 3 & 2 & 5 \\
\hline Future research career advice & 0 & 5 & 5 \\
\hline No personal connection & 2 & 2 & 4 \\
\hline Treats students as immature & 4 & 0 & 4 \\
\hline Insufficient communication & 2 & 1 & 3 \\
\hline Intimidated by mentor & 2 & 1 & 3 \\
\hline Meetings & 23 & 17 & 40 \\
\hline Insufficient meetings & 13 & 8 & 21 \\
\hline Productive meetings & 5 & 7 & 12 \\
\hline Unhelpful meetings & 5 & 2 & 7 \\
\hline Metaskills & 6 & 14 & 20 \\
\hline Helps with teamwork & 6 & 7 & 13 \\
\hline Independence in research & 0 & 7 & 7 \\
\hline
\end{tabular}

Perhaps in part because students were so early in their undergraduate careers, they appreciated being given specific tasks, much as they are used to in their coursework. Conversely, while students appreciated that research is more open-ended than coursework, they reported feeling confused, lost, or intimidated at being given too much independence or "assigned" tasks they felt weren't specific enough, as illustrated in the following excerpt:

[The technical advisor]... [gives] us more freedom to make our own decisions of where we want to take our research. While I understand how this will allow our group to grow more, I believe that it has led me to feel unsure of how to ask for technical support.

Students also viewed their mentors as sources of technical information and help, frequently mentioning that mentors answered their questions and proactively taught content. One student wrote:

Our advisor provides us with more technical support and ideas that can push us along the path that our faculty advisor wants.
This includes reviewing our code, helping us debug, suggesting new techniques to look into, as well as tiny shifts in our algorithm.

This student appreciates that the mentor is playing the role of tutor (debugging, providing hints when solving problems), perhaps because it makes the unknown of research feel more like the course structures they are comfortable with.

The remaining themes in Table 1-Interpersonal, Meetings and Metaskills-highlight aspects of the mentoring relationship more related to the research process than the actual content of the work. In this domain, students primarily reflected on the friendliness and approachability of their mentors, as well as how available their mentors were for meetings.

The perceived friendliness of a mentor was one of the most important characteristics of a positive mentoring relationship. We coded a response with "Friendliness/emotional support" when students wrote about mentors demonstrating a personal connection or showing concern for students' emotional state. This characteristic made students more comfortable asking technical questions, as illustrated by the following response:

She also keeps the mentor/student relationship more casual and friendly so it makes it easy to tell her about any difficulties we're having.

While struggle is commonly seen for undergraduate researchers, this is especially true for early undergraduates who may be confused about basic concepts and have a large number of what they might perceive to be "stupid questions." A mentor who explicitly puts the student at ease facilitates the teaching part of the mentoring relationship, which is so clearly important for early undergraduates.

Friendliness also seemed to be a quality that required proactive effort. Even when mentors say that students should feel comfortable, this result is not always achieved with a hands-off approach, as the following response illustrates:

He takes a hands-off approach but if we ask, he will always give us advice and point us in a better direction... I'm not really sure what to ask him sometimes... It's still intimidating for me to meet with him, I feel I barely know anything compared to him, but he's expressed that we can be comfortable with him.

In contrast, friendly mentors invite questions, as described in the following response:

[Central mentor] is approachable and easy to talk to; she does not make any of us feel inadequate for asking basic questions.

Students with more approachable mentors are no more sure what to ask, but the fact that they feel comfortable asking the "wrong" question helps them open up.

Although responses with negative sentiment were infrequent, the ones that did occur often co-occurred with insufficient meeting availability, insufficient technical support, or a feeling that the mentor was not respecting the student. Just as they expect a smooth learning experience in their courses from their teachers, early undergraduates need and expect their research mentors to give them sufficient support. One student wrote:

I don't think I have a good relationship with my research advisor. I barely see him and when I see him there is very little 
Table 2: Technical mentor's top ten most frequent codes

\begin{tabular}{cc} 
Code/Theme & Counts \\
\hline Provides technical support & 70 \\
Provides guidance on next steps & 54 \\
Friendliness/emotional support & 43 \\
Answers questions & 43 \\
Explains concepts/teaches & 34 \\
Constructive feedback & 23 \\
Provides other sources of help & 23 \\
Good communication & 21 \\
Not enough guidance from mentors & 17 \\
Big-picture context & 16 \\
\hline
\end{tabular}

interaction and it is a bit awkward in my opinion. Last quarter I believe we only met with him about 3 or 4 times.

Students also reacted negatively when mentors seemed not to respect their point of view, as illustrated by this student's response:

My relationship with my advisor is not the best. Sometimes I feel that they do not want to listen to our input and idea and only care about theirs. Whenever we think of an idea they automatically think of 5 different ways that it could be bad and why we shouldn't do it.

A seasoned researcher reading this experience likely perceives that the mentor is actually highly engaged, pushing back to encourage lively research debate, but that is not the way an early undergraduate perceives the mentor's reaction.

\subsection{RQ2: Complementary Mentoring Roles}

To understand the roles played by the technical mentor and the central mentor, we examined the codes that occurred most frequently when students reflected on their relationship with each mentor. The ten most frequently occurring codes for the technical and central mentors are summarized in Tables 2 and 3, respectively.

Students generally perceived the role of the technical mentor positively, appreciating project-related, process-related, and personal mentoring. However, students across the program also felt their technical mentor did not provide enough guidance. The code "Not enough guidance from mentors" appeared for 17 students across 12 groups, of 18 total groups.

Similarly Table 3 shows that the central mentor also played a largely positive role, providing guidance on next steps and acting as a liaison to the technical mentor. However, 10 students, all from one university, felt they had insufficient number of meetings with this mentor. This feeling was almost always attributed to the mentor canceling meetings (often at the last minute) rather than a systemic lack of interaction. As such, this issue is likely due to the workload of the student chosen as central mentor rather than the structure of the program itself.

By analyzing Tables 2 and 3, we start to get a picture of the complementary roles that mentors played. A prominent dynamic was that, for many students, lower-level technical help tended to come from the technical mentors and higher-level project guidance tended to be from the program's central mentor. One student's reflections capture this synergy well:
Table 3: Central mentor's top ten most frequent codes

\begin{tabular}{cc} 
Code/Theme & Counts \\
\hline Provides guidance on next steps & 64 \\
Liaison between advisors & 21 \\
Provides technical support & 21 \\
Big-picture context & 20 \\
Asks questions about research & 19 \\
Friendliness/emotional support & 19 \\
Constructive feedback & 18 \\
Helps with teamwork & 14 \\
Explains concepts/teaches & 13 \\
Insufficient meetings & 10 \\
\hline
\end{tabular}

[Technical mentor] ... [has been] guiding us on how to use open-source libraries for building machine learning models, sending us tutorials to follow, and showing us how to work with large datasets.

[Central mentor] has helped us keep track of our progress ... Her advising is more generic and is in regards to the overall pace we're moving at as well that the division of labor within our group, whereas our technical advisor is more concerned with the details of our project.

This dynamic makes sense (only the technical mentor has specific low-level expertise), and it shows that the dual mentoring structure is working as intended. The central mentor is freeing up time for the technical mentor to focus on low-level details by helping with high-level and contextual mentoring support.

A related trend that emerges is that students tend to ask questions of their technical mentors and to be asked questions by the central mentor. Technical mentors provided an insider's perspective and so could answer fine-grained technical questions, while the central mentor's questions helped students contextualize their work, as described by the following reflection:

It's great that [central mentor]... can question the logic of our work and help us understand the motivations of our work better by doing so.

We also compared the relative code frequencies between the two types of mentor. For each code in Table 1 that occurred more than $1 \%$ of the time in our data, we calculated how often that code applied to each type of mentor. These results are shown in Figure 1. Bars to the left and right indicate codes that were more often applied to responses about the central and technical mentor, respectively.

Figure 1 shows more support for the complementary roles suggested by Tables 2 and 3. The central mentor's role was at a higher level, focused on issues of teamwork, communication, and bigpicture contextualization (through question-asking), while students depended on the technical mentor as a technical guide who they looked to for resources and answers to their questions. Figure 1 also shows that the central and technical mentors played some roles to a similar extent: helping students understand the big picture of their project, providing guidance on next steps, providing constructive feedback. As observed before, students felt that they would have liked more meetings with both mentors and more technical support from both mentors. 


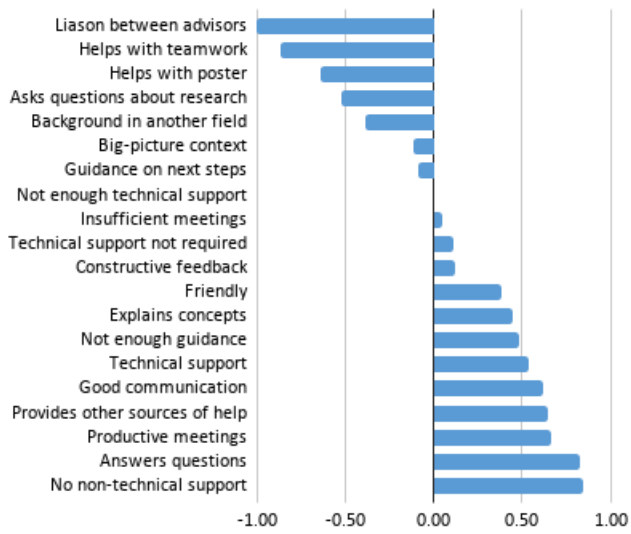

Figure 1: Difference in code frequencies for central (left) vs. technical (right) mentors

\subsection{RQ3: Mentoring Relationships over Time}

Overall, mentoring relationships were largely stable between winter and spring. Table 1 shows the relative frequency of most codes did not change. Some new codes surfaced in the spring data related to end-of-program results and growth in students' research identity.

Generally, mentoring relationships improved with time. Students felt they received enough project guidance more often, and their comfort with research independence grew (Table 1). We verified that this trend is not due to a lack of spring data from students who expressed these sentiments in the winter. Additionally, there were 6 students who had an overall negative mentoring relationship in winter, but all of these improved to neutral or positive in spring. Reasons for these improvements included better communication, more technical support, and students becoming more comfortable with their mentors. Often, this improvement seemed to be due to a change on the part of the student. For example one student wrote:

Previously it felt that we were not getting enough attention from our advisors, but now we have tried to take more of an initiative in reaching out to them more often. By being more proactive, I think that our relationship is improving and our advisors are more interested in helping us.

On the other hand, 2 students' relationships worsened in the spring, both due to unmet or compounding expectations. In one of these cases, the student had hoped in winter for a social relationship with the mentor and lab members, writing:

I would like my advisor to be a connection between the other lab members.

However in the spring the student was dissatisfied with the lack of improvement in atmosphere, writing:

We only interact if my team has questions for him and he does not really reach out to us in any way... Outside of that, we don't really talk or understand one another.

\section{DISCUSSION}

Our findings indicate that a dual-mentoring structure effectively engages early undergraduates in research, as only a small number of students (less than 10\%) reported overall negative relationships with their mentors, and those relationships improved over time. Further, the mentorship level seems adequate considering the high retention rates in the program ( $98 \%$ for the cohort under study).

It is unsurprising that early undergraduates need a lot of projectrelated and emotional support. The question is: Can the mentoring load be shared between the technical mentor (typically a faculty member) and a central mentor who doesn't necessarily have domain expertise? Our results suggest yes. We found the central mentor can provide high-level support and share in the project guidance, helping students to reflect on their research, think more deeply, and ask their technical mentors questions. Although it may seem counterintuitive, this freed faculty/technical mentors to provide more of the critical low-level support to students, which is something the central mentor cannot provide.

We found that students tended to see research as a series of assignments to complete rather than an independent discovery process. However, we observed some growth and comfort with less guided research as the program progressed. This confirms prior findings that projects for early undergraduates should be appropriately scoped [23].

Although the program has a heavy emphasis on diversity, few students reported receiving life or career mentoring and none mentioned diversity-related discussions with their mentors. It is unclear whether students didn't report on such type of mentoring because they were not explicitly prompted to do so or if they never received it. While the ratio between men and women in the data set was relatively even, and students from traditionally underrepresented racial and ethnic groups were fairly well-represented, we did not find conclusive differences in experiences by student demographics.

The main limitations of our findings arise from differences and biases among the qualities of the mentors and coding subjectivity.

Qualities of mentors. We did not control for several differences among mentors. First, we expect some level of selection bias among the mentors. All faculty mentors were volunteers, and as such they tended to be more committed to providing a positive research experience and more cognizant of diversity issues. We cannot conclude that mentoring relationships would have been as successful with a broader pool of mentors. Second, while the central mentor was supported by a stipend, the technical mentors were not explicitly compensated for mentoring. This may have impacted the level of commitment among the two types of mentors. Finally, due to the central mentor's position as mentor to every group, any issues with that mentor would be amplified across all groups.

Subjectivity of coding. We expect some level of subjectivity and the possibility for human error in the coding process. Although most codes were straightforward, evaluating the overall sentiment of an excerpt may be debatable, as it was sometimes difficult to define an absolute distinction between positive and neutral excerpts.

\section{CONCLUSION}

This work shows how a dual-mentoring approach can effectively support early undergraduates in research, and examines the specific role of each mentor in a successful, and scalable, URE program. We hope that the CS education community will use these results to expand early undergraduate research opportunities, develop new mentoring models, and train faculty and graduate students who serve in mentoring roles. 


\section{ACKNOWLEDGMENTS}

This material is based upon work supported by the National Science Foundation under Grant Nos. DUE-1821521 and DUE-1821415. We would like to thank the participants of the research program for being willing to have their experiences and perceptions included in this study.

\section{REFERENCES}

[1] Christine Alvarado, Sergio Villazon, and Burcin Tamer. 2019. Evaluating a Scalable Program for Undergraduate CS Research. In Proceedings of the 2019 ACM Conference on International Computing Education Research (ICER '19). Association for Computing Machinery, New York, NY, USA, 269-277. https://doi.org/10. $1145 / 3291279.3339406$

[2] L. Barker. 2009. Student and Faculty Perceptions of Undergraduate Research Experiences in Computing. Trans. Comput. Educ. 9, 1, Article 5 (March 2009), 28 pages. https://doi.org/10.1145/1513593.1513598

[3] Michael Barrow, Shelby Thomas, and Christine Alvarado. 2016. ERSP: A Structured CS Research Program for Early-College Students. In Proceedings of the 2016 ACM Conference on Innovation and Technology in Computer Science Education (ITiCSE '16). Association for Computing Machinery, New York, NY, USA, 148-153. https://doi.org/10.1145/2899415.2899436

[4] Bethany Bowling, Heather Bullen, Maureen Doyle, and John Filaseta. 2013. Retention of STEM Majors Using Early Undergraduate Researchexperiences. In Proceeding of the 44th ACM Technical Symposium on Computer Science Education (SIGCSE '13). Association for Computing Machinery, New York, NY, USA, 171-176. https://doi.org/10.1145/2445196.2445249

[5] Angela M. Byars-Winston, Janet Branchaw, Christine Pfund, Patrice Leverett, and Joseph Newton. 2015. Culturally Diverse Undergraduate Researchers' Academic Outcomes and Perceptions of Their Research Mentoring Relationships. International fournal of Science Education 37, 15 (2015), 2533-2554. https://doi.org/10 1080/09500693.2015.1085133 arXiv:https://doi.org/10.1080/09500693.2015.1085133

[6] S. R. Gregerman, J. S. Lerner, W. von. Hippel, J. Jonides, and B. A. Nagda. 1998 Undergraduate Student-Faculty Research Partnerships Affect Student Retention. The Review of Higher Education 22, 1 (1998), 55-72.

[7] Ben Jelen, Julia Dunbar, Susan Monsey, Olivia K. Richards, and Katie A. Siek. 2019. Utilizing the Affinity Research Group Model in a Summer Research Experience for Undergraduates Program. In Proceedings of the 50th ACM Technical Symposium on Computer Science Education (SIGCSE '19). Association for Computing Machinery, New York, NY, USA, 990-996. https://doi.org/10.1145/3287324.3287501

[8] W. Brad Johnson. 2002. The intentional mentor: Strategies and guidelines for the practice of mentoring. Professional Psychology: Research and Practice 33, 1 (2002), 88-96. https://doi.org/10.1037/0735-7028.33.1.88

[9] W Brad Johnson and Jennifer M Huwe. 2003. Getting mentored in graduate school. American Psychological Association.

[10] Karen A. Kim, Amy J. Fann, and Kimberly O. Misa-Escalante. 2011. Engaging Women in Computer Science and Engineering: Promising Practices for Promoting Gender Equity in Undergraduate Research Experiences. ACM Trans. Comput. Educ. 11, 2, Article 8 (July 2011), 19 pages. https://doi.org/10.1145/1993069. 1993072

[11] Helena Chmura Kraemer. 1980. Extension of the Kappa Coefficient. Biometrics 36, 2 (1980), 207-216. http://www.jstor.org/stable/2529972

[12] Belle Liang, Allison J. Tracy, Catherine A. Taylor, and Linda M. Williams. 2002. Mentoring College-Age Women: A Relational Approach. American fournal of Community Psychology 30, 2 (2002), 271-288. https://doi.org/10.1023/A: 1014637112531

[13] Moira Maguire and Brid Delahunt. 2017. Doing a thematic analysis: A practical, step-by-step guide for learning and teaching scholars. All Ireland fournal of Higher Education 9, 3 (2017). https://ojs.aishe.org/index.php/aishe-j/article/view/335

[14] Diba Mirza, Deeksha Dangwal, and Timothy Sherwood. 2019. PyRTL in Early Undergraduate Research. In Proceedings of the Workshop on Computer Architecture Education (WCAE'19). Association for Computing Machinery, New York, NY, USA, Article 6, 8 pages. https://doi.org/10.1145/3338698.3338890
[15] National Academies of Sciences, Engineering, and Medicine. 2017. Undergraduate Research Experiences for STEM Students: Successes, Challenges, and Opportunities. The National Academies Press, Washington, DC. https://doi.org/10.17226/24622

[16] Ama Nyame-Mensah. 2015. Strengthening the computing research pipeline through minority participation: The case for undergraduate research experiences. In 2015 Research in Equity and Sustained Participation in Engineering, Computing, and Technology (RESPECT). IEEE, 1-7.

[17] Matea Pender, Dave Marcotte, Mariano Sto. Domingo, and Kenneth Maton. 2010. The STEM Pipeline: The Role of Summer Research Experience in Minority Students' Graduate Aspirations. education policy analysis archives 18 (2010).

[18] Christine Pfund, Angela Byars-Winston, Janet Branchaw, Sylvia Hurtado, and Kevin Eagan. 2016. Defining Attributes and Metrics of Effective Research
Mentoring Relationships. AIDS and Behavior 20, S2 (April 2016), 238-248. https://doi.org/10.1007/s10461-016-1384-z

[19] Audrey Smith Rorrer, Joseph Allen, and Huifang Zuo. 2018. A National Study of Undergraduate Research Experiences in Computing: Implications for Culturally Relevant Pedagogy. In Proceedings of the 49th ACM Technical Symposium on Computer Science Education (SIGCSE '18). Association for Computing Machinery, New York, NY, USA, 604-609. https://doi.org/10.1145/3159450.3159510

[20] Mark Santolucito and Ruzica Piskac. 2020. Formal Methods and Computing Identity-Based Mentorship for Early Stage Researchers. In Proceedings of the 51st ACM Technical Symposium on Computer Science Education (SIGCSE '20). Association for Computing Machinery, New York, NY, USA, 135-141. https: //doi.org/10.1145/3328778.3366957

[21] Jenny Olin Shanahan, Elizabeth Ackley-Holbrook, Eric Hall, Kearsley Stewart, and Helen Walkington. 2015. Ten Salient Practices of Undergraduate Research Mentors: A Review of the Literature. Mentoring \& Tutoring: Partnership in Learning 23, 5 (2015), 359-376. https://doi.org/10.1080/13611267.2015.1126162 arXiv:https://doi.org/10.1080/13611267.2015.1126162

[22] Jane G. Stout, N. Burçin Tamer, and Christine J. Alvarado. 2018. Formal Research Experiences for First Year Students: A Key to Greater Diversity in Computing?. In Proceedings of the 49th ACM Technical Symposium on Computer Science Education (SIGCSE '18). ACM, New York, NY, USA, 693-698. https: //doi.org/10.1145/3159450.3159472

[23] Jane G. Stout, N. Burçin Tamer, and Christine J. Alvarado. 2018. Formal Research Experiences for First Year Students: A Key to Greater Diversity in Computing?. In Proceedings of the 49th ACM Technical Symposium on Computer Science Education (SIGCSE '18). ACM, New York, NY, USA, 693-698. https: //doi.org/10.1145/3159450.3159472

[24] Burçin Tamer and Jane G. Stout. 2016. Understanding How Research Experiences for Undergraduate Students May Foster Diversity in the Professorate. In Proceedings of the 47th ACM Technical Symposium on Computing Science Education (SIGCSE '16). ACM, New York, NY, USA, 114-119. https://doi.org/10.1145/ 2839509.2844573

[25] Rahman Tashakkori, Barry L. Kurtz, Dolores A. Parks, James B. Fenwick, and Alice A. McRae. 2011. Early Participation of CS Students in Research. In Proceedings of the 42nd ACM Technical Symposium on Computer Science Education (SIGCSE '11). Association for Computing Machinery, New York, NY, USA, 63-68. https://doi.org/10.1145/1953163.1953185

[26] Heather Thiry and Sandra Laursen. 2011. The Role of Student-Advisor Interactions in Apprenticing Undergraduate Researchers into a Scientific Community of Practice. Fournal of Science Education and Technology 20 (12 2011), 771-784. https://doi.org/10.1007/s10956-010-9271-2

[27] Elsa Q. Villa, Kerrie Kephart, Ann Q. Gates, Heather Thiry, and Sarah Hug. 2013. Affinity Research Groups in Practice: Apprenticing Students in Research. Fournal of Engineering Education 102, 3 (2013), 444-466. https://doi.org/10.1002/jee.20016 arXiv:https://onlinelibrary.wiley.com/doi/pdf/10.1002/jee.20016

[28] Jennifer H Waldeck, Victoria O Orrego, Timothy G Plax, and Patricia Kearney. 1997. Graduate student/faculty mentoring relationships: Who gets mentored, how it happens, and to what end. Communication Quarterly 45, 3 (1997), 93-109.

[29] Helen Walkington, Kearsley A. Stewart, Eric E. Hall, Elizabeth Ackley, and Jenny Olin Shanahan. 2020. Salient practices of award-winning undergraduate research mentors-balancing freedom and control to achieve excellence. Studies in Higher Education 45, 7 (2020), 1519-1532. https://doi.org/10.1080/03075079. 2019.1637838 arXiv:https://doi.org/10.1080/03075079.2019.1637838 